Gut, 1986, 27, S1, 72-75

\title{
Role of nutrition in inflammatory bowel disease: an overview
}

\author{
M L CLARK \\ From the Department of Gastroenterology, St Bartholomew's Hospital, London
}

SUMMARY Although many patients with inflammatory bowel disease are malnourished, the role of nutritional support is still controversial. It is universally accepted that with adequate nutritional support patients will put on weight and that their biochemical functions may improve; the question nevertheless remains: does this help the patient get over his or her disease more quickly and, more importantly, does this affect morbidity and mortality? There are several ways of providing nutritional support and all need careful evaluation.

\section{Nutritional supplements}

There are few scientific data supporting the use of dietary supplements in inflammatory bowel disease. Most clinicians, however, advocate a high calorie high nitrogen intake, particularly in severely malnourished patients with Crohn's disease.

The major cause of weight loss is anorexia, and trying to get patients to take a high calorie diet is often difficult. This is usually achieved with the help of steroids to reduce the inflammatory process. Corticosteroids make patients feel better, become less toxic, and improve their appetite so that they begin to take extra calories, often of their own volition. Steroids also directly stimulate the appetite.

Extra supplements can be given by encouraging the patient to eat larger amounts of ordinary food or by prescribing additional high calorie liquid diets. These, however, are often unpalatable, and ill patients do not therefore increase their overall calorific intake unless supplemental feeding is carefully supervised. Nutritional supplements do have a small role in helping sick patients to obtain some calories when they are extremely ill, but their overall value is doubtful.

\section{Parenteral nutrition}

Dudrick et $\mathrm{al}^{1}$ in 1969 were the first to suggest that parenteral nutrition was safe and possibly beneficial to patients with inflammatory bowel disease.

Correspondence to: Dr M L Clark, Department of Gastroenterology, St Bartholomew's Hospital, West Smithfield, London EC1A 7BE, England.
In the early 1970 s parenteral nutrition began to be used for inflammatory bowel disease, and several isolated reports suggested that this form of treatment might be helpful. Unfortunately, more time was spent on giving parenteral nutrition than was spent on considering its necessity.

Fischer $e t a l^{2}$ showed that the nutritional variables in 13 patients with inflammatory bowel disease improved with parenteral nutrition; many of these patients went into remission, without the need for surgery. Reilly $e t a l^{3}$ reviewed the histories of 34 patients with inflammatory bowel disease who were given parenteral nutrition in addition to other standard medical treatment, mainly corticosteroids. All patients had failed to improve with steroid treatment alone. The patients with Crohn's disease (mainly in the small bowel) gained weight, improved in well being, with loss of diarrhoea and abdominal pain. Again surgery was unnecessary in many of these patients. Further encouraging results were obtained by Vogel et al, ${ }^{4}$ by Dudrick et al, ${ }^{5}$ and Mullen et al. ${ }^{6} \mathrm{~A}$ review by Driscoll and Rosenberg ${ }^{7}$ of the value of total parenteral nutrition in inflammatory bowel disease supported the view that short term improvement seemed to occur in most patients treated in this way. It soon became apparent that these gains were, however, only short term and stopping parenteral nutrition inevitably led to a relapse of the disease.

In Crohn's disease three quarters of the patients may well have a remission. This, however, is not usually directly attributable to the parenteral nutrition alone as most patients have also been treated with standard medical treatment. Long term remissions are unusual after parenteral nutrition, and in my experience these remissions are virtually non- 
existent. I do not therefore advocate the use of parenteral nutrition in most cases of Crohn's disease.

I suggest that the use be confined to severely malnourished patients about to undergo surgery. I always start preoperative parenteral nutrition many days, and often weeks, before surgery and continue it for at least a further seven days. This use of parenteral nutrition is only based on a small number of cases and, like others, ${ }^{4}$ I have no comparative data on morbidity and mortality.

Vogel et $a l^{4}$ gave six patients with inflammatory bowel disease preoperative parenteral nutrition, and although they reported excellent results, they admitted that the results did not differ that much from those of patients with Crohn's disease who had a resection without preoperative nutrition. This illustrates the difficulty of evaluating parenteral nutrition and is the reason I use parenteral nutrition only in severely malnourished patients.

There have been few good controlled clinical trials on the use of parenteral nutrition in inflammatory bowel disease. Dickinson $e t \mathrm{al}^{8}$ studied two groups of patients (19 in each group) with acute colitis who were treated conventionally, but one group had their normal diet supplemented with parenteral nutrition. In each group there were some patients with Crohn's disease and some with ulcerative colitis, but there were more patients with Crohn's disease in the group without parenteral nutrition (six compared with three), which may have biased the results of the study. Nevertheless, in terms of morbidity, mortality, length of stay in hospital and the number of patients requiring surgery there was no difference between these groups, and the authors concluded that there was no advantage in adding parenteral nutrition to the standard medical regimen for the treatment of acute colitis.

In Oxford parenteral nutrition was added to the standard Truelove regimen for the treatment of acute colitis in the $1970 \mathrm{~s}$. Truelove et al ${ }^{9}$ reviewed the results of the treatment over two decades: they could only conclude that "parenteral nutrition appeared to add little to the acute management of colitis."

These findings support other uncontrolled studies, all of which show that this form of treatment is of little value in acute colitis. Parenteral nutrition may occasionally be useful in the rare severely malnourished patient with colitis as an adjunct to surgery, but its use does not prevent colectomy.

Total parenteral nutrition has also been used in patients with Crohn's disease with either enteral or enterocutaneous fistulae. A review published in $1978^{7}$ showed that 67 patients with fistulae had been treated with parenteral nutrition with an overall healing rate of $43 \%$. Thirty per cent of the fistulae still remained closed at three months. McIntyre et $a l^{10}$ reviewed the treatment of 48 patients with Crohn's disease who were given parenteral nutrition as part of their overall care. Some had their oral intake limited to small quantities of water, but others had a normal dietary intake. Most of the fistulae required a surgical procedure to effect a cure, but the mortality in the series was lower than that of previous studies, and it was concluded that the reason for this was that the patients were in a better nutritional state for surgery. Our experience with Crohn's fistulae treated with total parenteral nutrition and bowel rest has been extremely disappointing in the long term. We have usually been able to obtain reduction in fistula output in all patients, but as soon as parenteral nutrition is stopped and normal dietary intake is started the fistula begins draining once more. Total parenteral nutrition has therefore only been useful as an adjunct to the surgical treatment of the fistula. In general, therefore, in cases of Crohn's disease and ulcerative colitis parenteral nutrition is only of limited use as an adjunct to surgical treatment.

Parenteral nutrition, however, can be of quite considerable value in certain cases of Crohn's disease.

\section{GROWTH FAILURE IN CHILDREN}

About one third of children with Crohn's disease show delayed linear growth with delayed onset of puberty. Layden et al, ${ }^{11}$ Grand $e t$ al, ${ }^{12}$ and Kelts $e t$ $a l,{ }^{13}$ showed that adolescents treated with parenteral nutrition gained weight and increased linear growth, with an appreciable increase in growth velocity. In all cases symptoms remitted and in many puberty occurred, although surgery was still needed in some patients. ${ }^{14}$

Total parenteral nutrition, therefore, seems to be of value in patients with growth retardation, but it has now largely been replaced by enteral nutrition.

\section{SHORT BOWEL SYNDROME}

A small group of patients with inflammatory bowel disease who have surgery are left with a severe short bowel syndrome. A number of these require home parenteral nutrition, and the experience of this treatment in England and Wales was reviewed in 1980. Nine patients with extensive disease with multiple fistulae, as well as the short bowel syndrome, were treated with home parenteral nutrition. At that time most had been treated for six months only, with many of the patients eventually being able to maintain a good nutritional state by oral intake. There seems little doubt, therefore, that 
in this small group of patients home parenteral nutrition has a valuable role in the treatment of inflammatory bowel disease.

\section{Enteral nutrition}

Enteral nutrition became more popular as the expense, complications, and limited value of parenteral nutrition were understood. Enteral nutrition, using either liquidised foods or elemental diets, began to be used in the treatment of Crohn's disease in the late 1960s with little or no scientific support. Anecdotal reports appeared, and most clinicians thought that such treatment could do no harm.

Steven and Randall ${ }^{15}$ reported increases in body weight and improvement in biochemical functions and well being, with an elemental diet given orally for 40 days. Glotzer ${ }^{16}$ gave an elemental diet orally for 70 weeks and Goode et $\mathbf{l}^{17}$ fed an elemental diet for up to one year in eight patients with Crohn's disease. Three patients were given the diet preoperatively and five postoperatively: all showed an increase in weight. All these studies showed an improvement in nutrition, but mostly in the short term. Enthusiasm wained, however, partly because patients found the unpalatable elemental diets difficult to take over a long period.

In my department elemental diets have been used in a small number of patients with Crohn's disease in addition to a standard treatment regimen of steroids and azathioprine. These diets proved of little value in most patients. The most severely malnourished patients would not tolerate the diet and therefore required parenteral nutrition, while the remainder managed a normal diet.

Elemental diets were thought to be of value in patients with Crohn's disease and fistulae, either single or multiple. Voitk $e t a l^{18}$ reported the use of elemental diets for gastrointestinal fistulae and reported a reduction in mortality from about $50 \%$ to $28 \%$.

Kaminski and Deitel ${ }^{19}$ successfully treated several patients with inflammatory bowel disease with an elemental diet, the fistulae often closing spontaneously without surgical intervention. In the cases in my department the fistulae often closed, but as soon as the patient was returned to a normal diet the fistulae reopened. Once again surgery was the main means of treating such patients.

Following the success of parenteral nutrition in reversing growth failure in children and adolescents with Crohn's disease, Kirschner et al ${ }^{20}$ reported seven children with Crohn's disease and growth failure whose calorific intake was doubled by increasing their food intake and also by additional liquid supplements. All patients increased their growth velocity, and these authors emphasised the importance of improved nutrition in preventing growth retardation in children with Crohn's disease. This treatment requires the constant attention of parents and nursing staff, because when oral liquid diets are started in these ill children the normal food intake often decreases. ${ }^{21}$

Rosenthal $e t a l^{22}$ reviewed the important role of nutrition in reversing growth failure in children with Crohn's disease. Farthing et $a l^{21}$ were able to show abnormalities in growth hormone production in some children with Crohn's disease but not in others. Treatment either with steroids or surgery increased growth velocity - often considerably provided the patient went into remission and that this was independent of a change in growth hormone output. They also showed other abnormalities of the hypothalamus and pituitary axis and felt that these were due to the general ill health of these children. Improved nutrition was of some value but remission of the disease was also important in initiating growth.

A new interest in enteral nutrition and Crohn's disease was brought about by the paper of O'Morian et al in $1980 .{ }^{23}$ These workers treated 27 patients with acute Crohn's disease ( 32 acute episodes) with four weeks of elemental diet. Twenty nine went into remission clinically and biochemically, and at six months only six had relapsed.

In 1984 these same workers reported the result of a clinically controlled trial comparing prednisolone with an elemental diet for acute Crohn's disease. ${ }^{24}$ The patients were treated for four weeks and at the end of this time the improvement in all patients that is clinical, haematological, and biochemical was the same for both treatment groups. This exciting result was not only of practical interest but once again encouraged the idea that elemental diets might have some additional role in treatment, other than just providing calories for the patient.

Sanderson et $a l^{25}$ performed a similar study in children at this hospital. Eight children were treated with an elemental diet for six weeks and compared in a double blind controlled study with a similar group of eight children treated with prednisolone. The improvement in disease activity, biochemical functions, as well as weight gain was the same in the two groups. Calorific intake was higher in the group receiving the elemental diet, but, nevertheless, it still raises the possibility that an elemental diet might reduce the antigen load to the gut or change the gut flora, thereby inducing the remission. This has, of course, important pathogenetic implications, perhaps showing for the first time that Crohn's disease could be caused by some dietary factor.

Nutrition is therefore important in inflammatory bowel disease in two ways: 
1 Nutritional support, either parenterally or enterally, is useful in severely malnourished patients with Crohn's disease. Its use, however, is limited as a supplement to other standardised regimens including surgery. It is of little value in ulcerative colitis, for which steroids and surgery are still the principal forms of treatment.

2 Elemental diets may be a suitable way of treating acute Crohn's disease, and more importantly, their use may throw some light on the aetiology and pathogenesis of this disease.

\section{References}

1 Dudrick SJ, Wilmore DW, Wars HM, Rhoads JE. Long-term total parenteral nutrition with growth, development and positive nitrogen balance. Surgery 1968; 64: 134

2 Fischer JE, Foster GS, Abel RM, et al. Hyperalimentation as primary therapy for inflammatory bowel disease. Am J Surg 1973; 125: 165.

3 Reilly J, Ryan JA, Strole W, et al. Hyperalimentation in inflammatory bowel disease. Am J Surg 1976; 131: 192.

4 Vogel CM, Corwin TR, Baue AE. Intravenous hyperalimentation in the treatment of inflammatory diseases of the bowel. Arch Surg 1974; 108: 460.

5 Dudrick SJ, MacFayden BV Jr, Daly JM. Management of inflammatory bowel disease with parenteral hyperalimentation. In: Clearfield HR, Dinoso VP Jr, eds. Gastrointestinal emergencies. New York: Grune and Stratton. 1976: 193-9.

6 Mullen JL, Hargrove W, Clark ML, Dudrick SJ, Fitts WT Jr, Rosato EF. Ten years experience with intravenous hyperalimentation and inflammatory bowel disease. Ann Surg 1978; 187: 523-9.

7 Driscoll RH Jr, Rosenberg IH. Total parenteral nutrition in inflammatory bowel disease. Med Clin North Am 1978; 62: 185-201.

8 Dickinson RJ, Ashton MG, Axon ATR, Smith RC, Yeung K, Hill GL. Controlled trial of intravenous hyperalimentation and total bowel rest as an adjunct to the routine therapy of acute colitis. Gastroenterology 1980; 79: 1199-204.

9 Truelove SC, Willoughby CP, Lee EG, Kettlewell MGW. Further experience in the treatment of severe attacks of ulcerative colitis. Lancet 1978; ii: 1086.

10 McIntyre PB, Richie JK, Hawley PR, Bartram CI, Lennard-Jones JE. Management of enterocutaneous fistulas: a review of 132 cases. Br J Surg 1984; 71: 293-6.

11 Layden T, Rosenberg J, Nemchausky B, Elston C, Rosenberg I. Reversal of growth arrest in adolescents with Crohn's disease after parenteral alimentation. Gastroenterology 1976; 70: 1017-21.

12 Grand RJ, Shen G, Werlin SL et al. Reversal of growth arrest in Crohn's disease (CD): a new approach. Pediatr Res 1977; 11: 444.

13 Kelts DG, Grand RJ, Shen G et al. Nutritional basis of growth failure in children and adolescents with Crohn's disease. Gastroenterology 1979; 76: 720.

14 Lake AM, Kim S, Mathis RK, Walker WA. Influence of preoperative parenteral alimentation on postoperative growth in adolescent Crohn's disease. J Pediatr Gastroenterol Nutr 1985; 4: 182-6.

15 Stephens RV, Randall HT. Use of concentrated balanced liquid elemental diet for nutritional management of catabolic states. Ann Surg 1969; 170: 642-68.

16 Glotzer DJ, Silen W. Surgical management of regional enteritis. Gastroenterology 1971; 61: 751-6.

17 Goode A, Hawkins T, Feggeiter JGW, et al. Use of an elemental diet for long-term nutritional support in Crohn's disease. Lancet 1976; i: 122.

18 Voitk AJ, Echave V, Brown RA, McArle AH, Gurd FH. Elemental diet in the treatment of fistulas of the alimentary tract. Surg Gynecol Obstet 1973; 137: 68-72.

19 Kaminski VM, Deitel M. Nutritional support in the management of external fistulas of the alimentary tract. Br J Surg 1975; 62: 10().

20 Kirschner BS, Klich JR, Kalman SS, DeFavaro MV, Rosenberg IH. Reversal of growth retardation in Crohn's disease with therapy emphasizing oral nutritional restitution. Gastroenterology 1981; 80: 10-15.

21 Farthing MJG, Campbell CA, Walker-Smith JA, Edwards CRW, Rees LH, Dawson AM. Nocturnal growth hormone and gonadotrophin secretion in growth retarded children with Crohn's disease. Gut 1981; 22: 933 .

22 Rosenthal SR, Snyder JD, Hendricks KM, Walker WA. Growth failure and inflammatory bowel disease: approach to treatment of a complicated adolescent problem. Pediatrics 1983; 72: 481-90.

23 O'Morian C, Segal AW, Levi AJ. Elemental diets in treatment of acute Crohn's disease. $\mathrm{Br}$ Med J 1980; 281: 1173.

24 O'Morian C, Segal AW, Levi AJ. Elemental diets in treatment of acute Crohn's disease: a controlled trial. Br Med J 1984; 288: 1859-62.

25 Sanderson IR, Udeen S, Walker-Smith JA. A controlled trial of Vivonex versus Prednisolone in children with Crohn's disease. Arch Dis Child (In press). 